\title{
Determination of demantoid garnet origin by chemical fingerprinting
}

\author{
Clemens Schwarzinger ${ }^{1}[$
}

Received: 27 December 2018 / Accepted: 12 March 2019 / Published online: 29 April 2019

(c) The Author(s) 2019

\begin{abstract}
Demantoid garnets are among the most valuable gemstones in the world and their prices vary depending on the location they are found. Thus, a reference set of stones with known origins was assembled and their chemical composition analyzed with laser ablation-inductively coupled plasma mass spectrometry. It was shown that the three major sources, Russia, Namibia, and Madagascar, could be distinguished by using a plot of the manganese/titanium ratio versus the sum of chromium and vanadium in combination with the aluminum content. Even within Russia it was possible to separate some deposits using elemental composition despite some stones having color zones and therefore a varying concentration of some elements.
\end{abstract}

\section{Graphical abstract}

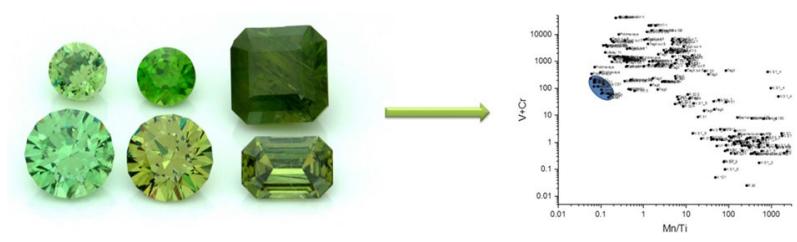

Keywords Mass spectroscopy $\cdot$ Gemmology $\cdot$ Minerals $\cdot$ Silicates $\cdot$ Trace elements $\cdot$ Spectroscopy

\section{Introduction}

This paper is dedicated to Prof. Heinz Falk on the occasion of his 80th birthday. He has not only been one of the most influential teachers I had, but we also share a common hobby: minerals. So, what could be more suitable than a paper on the combination of chemistry and minerals?

Garnets are a super group of minerals with the common formula $\mathrm{M}(\mathrm{II})_{3} \mathrm{M}(\mathrm{III})_{2}\left[\mathrm{SiO}_{4}\right]_{3}$, where $\mathrm{M}(\mathrm{II})$ are bivalent metals and $\mathrm{M}(\mathrm{III})$ are trivalent metals. They are further divided into ugrandites and pyralspites. Ugrandites have calcium in the M(II) position and either chromium (uwarowite), aluminum (grossular), or iron (andradite) in the M(III) position and pyralyspites all have aluminum in their $\mathrm{M}$ (III) position and magnesium (pyrope), iron (almandine), or manganese

Clemens Schwarzinger

clemens.schwarzinger@jku.at

1 Institute of Chemical Technology of Organic Materials, Johannes Kepler University Linz, Linz, Austria (spessartine) in the M(II) position. Additionally, garnets can form all kinds of solid mixtures and thus are often hard to classify [1]. Even more complex is the nomenclature of the gem trade. Here, often color or provenance is used to create names as they might sound more valuable to a customer, e.g., tsavorite for green grossular found in Eastern Africa or Malaya-meaning off color-garnets.

In this paper we will focus on the species andradite, which when of green color is called demantoid (Fig. 1). The name is derived from diamond and means diamond-like, which is due to the fact that demantoids, when properly cut, have an equal sparkle and play of color as diamonds. This is due to the rather high refractive index of 1.88 and the very high dispersion of 0.057 , which is even higher than that of diamond (0.044). Therefore, and because demantoids are much rarer than diamonds, they are highly priced [2].

Another factor that influences the price of gemstones is their provenance. While two gems might look similar in terms of color, cut, and clarity, their price can differ by several hundred percent if one can be assigned to a specific mine or at least a country, the best examples being sapphires 
Fig. 1 Demantoid gemstones from Namibia (front row) and Russia (back row, from left to right: Bashenovskoe, Bobrovka/ Tagil, Ufaley)

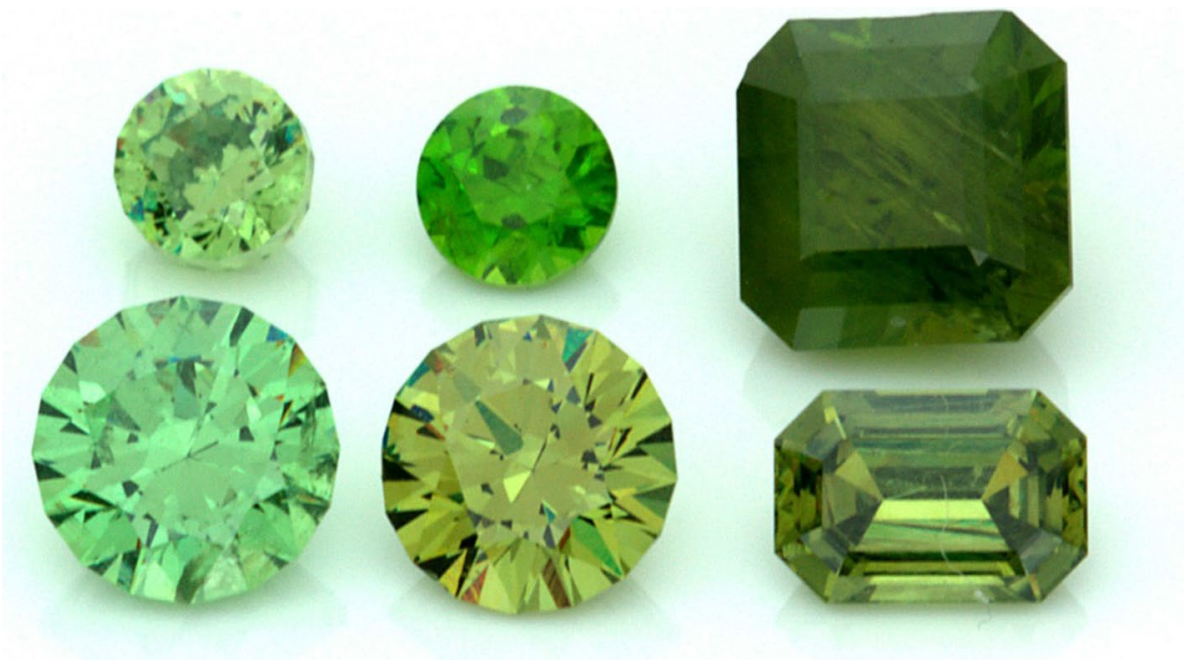

from Kashmir or rubies from Mogok, Myanmar. For demantoids, it is Russian origin that increases the value. Traditionally, these provenances are assigned by gemmologists based on inclusions and experience and thus are often called expert opinions-which means that two experts might assign two different origins for one gemstone.

Demantoids were originally found in the middle of the nineteenth century in the Ural Mountains of Russia [3, 4]: more exactly, in alluvial deposits in the River Bobrovka near the village Elizavetinskoye, close to Niznij Tagil, about $100 \mathrm{~km}$ north of Ekaterinburg. Later on other deposits were found in the Ural, roughly $90 \mathrm{~km}$ south of Ekaterinburg, which are Poldnevskoye (Poldnevaya), Karkodin, and Ufaley. The Poldnevskoye deposit is also located on River Bobrovka, but not the same as the one where the original finds were made, which makes correct assignment of the localities sometimes impossible.

In the 1990s a new deposit was found in Namibia in the Erongo Mountains close to Tubussis [5-7]. Unlike the Russian stones, they are formed in skarns with no to very little chromium content. The cause of the green color is assumed to be an iron-based chromophore. In its heydays the Green Dragon mine produced five to ten thousand carats per year, with mostly stones between 2 and $3 \mathrm{~mm}$, although very seldom cut stones of over $5 \mathrm{ct}$ were produced. In 2008/09, another deposit was discovered in the mangrove swamps of Antetezambato in Northern Madagascar providing excellent crystals which resemble the Namibian material in their appearance [8]. Besides those major deposits, many other places have yielded demantoids such as Iran, Pakistan, Italy, or Canada, but mostly not in qualities or quantities to be of commercial importance. A current (February 2019) market analysis at the world's largest gem shows in Tucson, USA, has shown that about $60-70 \%$ of all demantoids for sale are from Russia and around 25-30\% from Namibia. Madagascan gems are very rare as there seems to be no production at the moment and only one set of demantoids from Iran was for sale, as well as two stones from Canada.

In this paper, we will show that by using trace element analysis it is possible to differentiate between the most important countries of origin and even further in some cases between individual deposits.

\section{Results and discussion}

To be able to differentiate Russian stones from others, it is necessary to analyze and understand their chemistry first. We were able to obtain samples from all mentioned Russian localities, from Ufaley and Karkodin heated and unheated samples were available (heating of stones from these two localities is often necessary to remove the yellow tint and improve the green color) (Fig. 2) [9]. A special case comprises the demantoids from Ufaley which are found as brown to red (heating to green) or bicolor brown-green crystals. One of these color zoned samples has been sliced and its chemical composition was measured from the brown core via the intense green middle part to the yellowish-green rim to reveal the different concentrations of minor elements within a single crystal. XPS analysis confirmed the crystal to be almost pure andradite with no significant variations of the $\mathrm{Ca}, \mathrm{Fe}, \mathrm{Si}$, and $\mathrm{O}$ concentrations. Figure 3 shows that the concentration of titanium is highest in the brown core and gradually fades toward the outer part of the crystal. The intense green medium section, which is of highest commercial value, is dominated by chromium. Vanadium, which is very often also a reason of green color in minerals and sometimes even of more influence than chromium [10], does not seem to play an important role in the coloration of these garnets.

In a first attempt to assign correct origins, all Russian and Namibian stones were analyzed and trends within the 
Fig. 2 Rough demantoid samples from Russian localities. Left to right: Ufaley 1 (heated), Ufaley 1 (unheated), Ufaley 2 (unheated), Ufaley 2 (heated), Karkodin (unheated), Karkodin (heated), Poldnevaya (unheated), Bobrovka/Tagil (unheated)
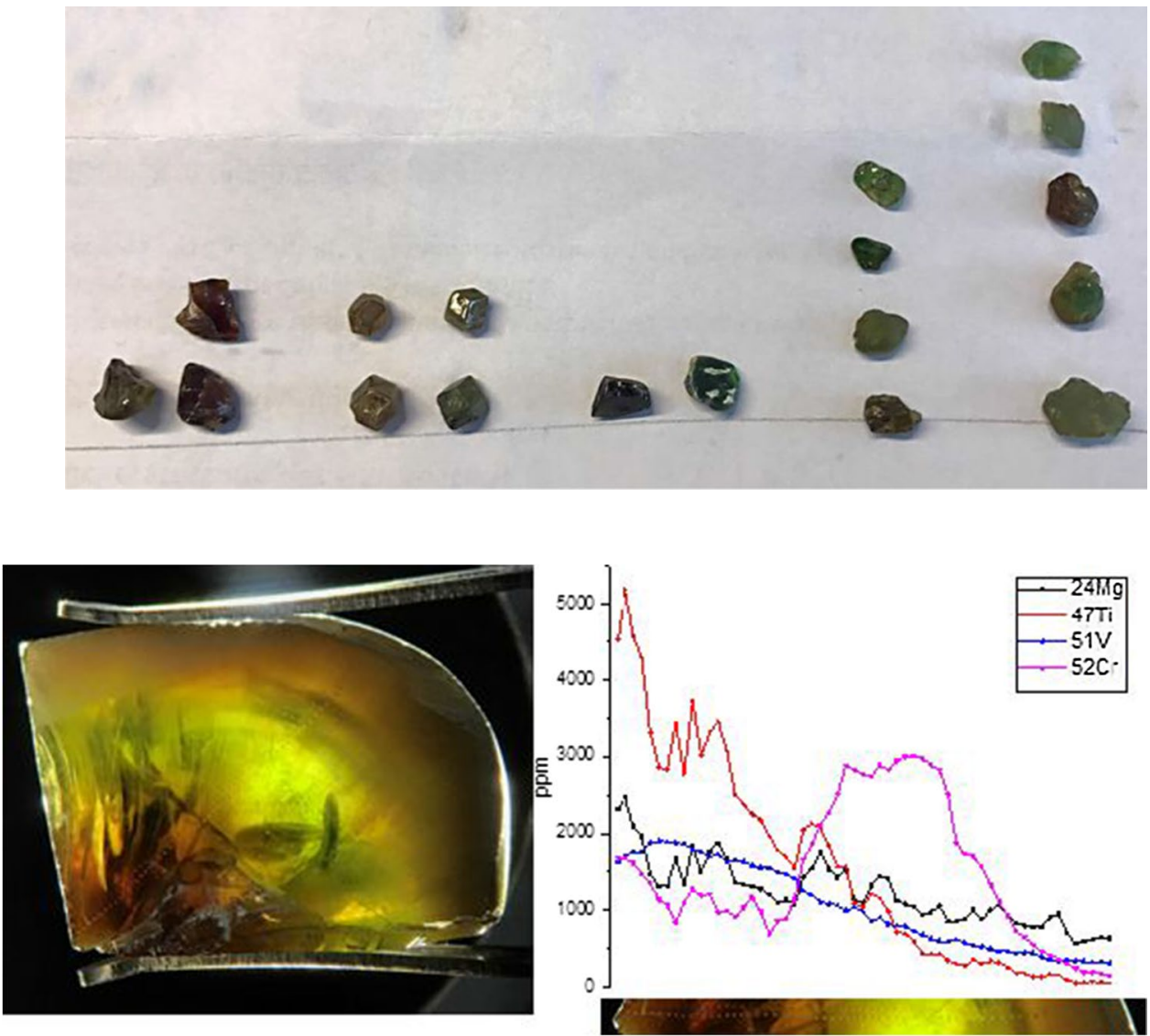

Fig. 3 Distribution of trace elements along a crystal section (from center to rim) showing high titanium concentrations in the center and highest chromium concentrations in the green sections chemical composition traced. It could soon be seen that most of the Russian stones have concentrations of $\mathrm{Cr}$ and $\mathrm{V}$ (green chromophores) in the range of 100-10000 ppm, whereas Namibian stones rarely have those elements at all. On the other hand, Mn could be found in Namibian stones in the range of $1-2 \%$, whereas in the Russian stones it was only present below $500 \mathrm{ppm}$. After some optimization, it was found that using the sum of $\mathrm{V}$ and $\mathrm{Cr}$ as well as the $\mathrm{Mn} / \mathrm{Ti}$ ratio as criteria, a very good separation of the 42 Russian and 23 Namibian stones is possible (Fig. 4a). Both values are plotted on logarithmic scales separating the localities well with only a narrow zone of uncertainty. Also, the results obtained from the multicolored Ufaley sample are displayed using this plot and, although they spread along the $\mathrm{Mn} / \mathrm{Ti}$ axis (Fig. 4b), a clear separation from the Namibian material is possible. The only Russian stones that cannot be separated are those from Bashenovskoe, but those are first of all rarities and not used commercially and can be distinguished from other demantoids as they typically have some percentage of grossular [personal communication Ildar Latypov].

Having a closer look at the Russian localities, it could be found that using the $\mathrm{Al} / \mathrm{Mg}$ ratio in combination with the $\mathrm{Mn} / \mathrm{Ti}$ ratio even an identification of some individual mines is possible (Fig. 5). The Ufaley material has the highest Al/ $\mathrm{Mg}$ ratios and the Bashenovskoe material the highest $\mathrm{Mn}$ /
Ti ratios, similar to the Namibian material. The deposits of Karkodin and Poldnevskoye are separated only by a few kilometers and therefore do not separate well in this diagram but form a group together. This group is only disturbed by a few spots assigned to the locality Bobrovka, which as stated in the introduction is either a river close to Elizavetinskoye where the original find was made or a river close to the Poldnevskoye deposit—so it is assumed that those samples are from the latter location. All other samples labeled Bobrovka or Russia are rather widespread in this plot, but show tentatively a lower $\mathrm{Al} / \mathrm{Mg}$ ratio. One of the reasons for this can be that at the River Bobrovka alluvial deposits have been mined, which means that the stones were not found in the spot where they originally formed, but were washed out by the river and transported along with gravel. It is possible that they originate from more than one primary deposit, thus explaining the rather broad chemical distribution.

The third commercially important location at the moment is Madagascar. The andradites from Antetezambato are formed in a geologically rather similar surrounding as in Namibia (skarn deposits) and also optically are more like their Namibian than their Russian counterparts. When using the $\mathrm{Mn} / \mathrm{Ti}$ versus sum of $\mathrm{Cr}$ and $\mathrm{V}$ approach, the stones from Madagascar are easily separated from the ones from Namibia by their very low $\mathrm{Mn} / \mathrm{Ti}$ ratio, but due to the fact 


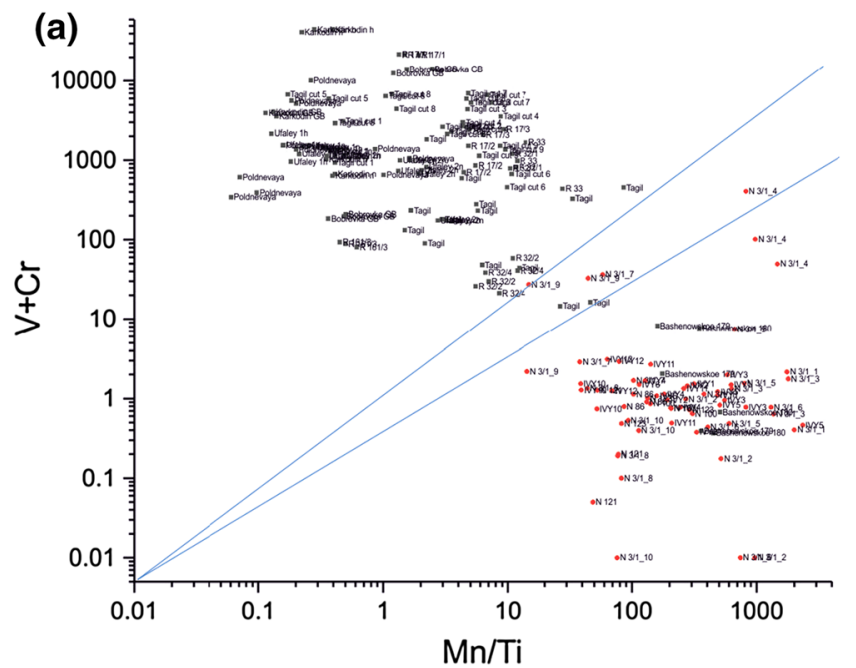

Fig. 4 a Separation of Russian and Namibian demantoids using trace a plot of manganese/titanium ratio vs. the sum of chromium and vanadium. Blue lines indicate the area of uncertainty; specimens from Bashenovskoe cannot be separated from Namibian gems using this

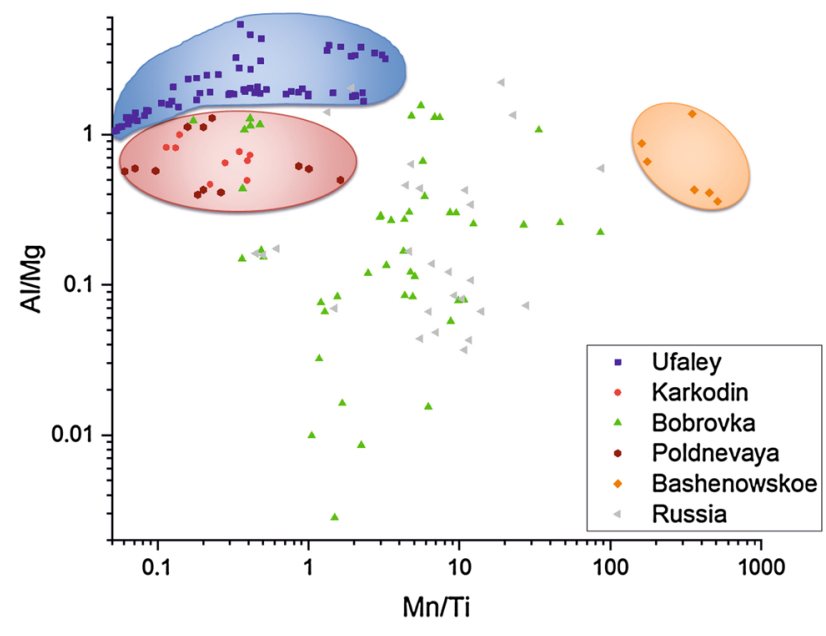

Fig. 5 Separation of Ural demantoids using trace element ratios of manganese/titanium and aluminum/magnesium

that some amount of $\mathrm{Cr}$ and/or $\mathrm{V}$ can be found they show up in the proximity of some Russian material (Fig. 6).

A very effective way to differentiate stones from Madagascar is by looking at their $\mathrm{Al}$ content. Namibian stones typically have way below 1000 ppm and Russian stones, although having a higher content of mostly up to $2000 \mathrm{ppm}$, with Ufaley stones being an exception with 1500-6500 ppm, are clearly lower in $\mathrm{Al}$ than the Madagascar samples. The $\mathrm{Al}$ concentration in stones from Madagascar has always been found to be higher than $11000 \mathrm{ppm}$ with maximum values being around $10 \%$ (it has to be noted that such concentrations are too high to be measured with LA-icp MS and tend

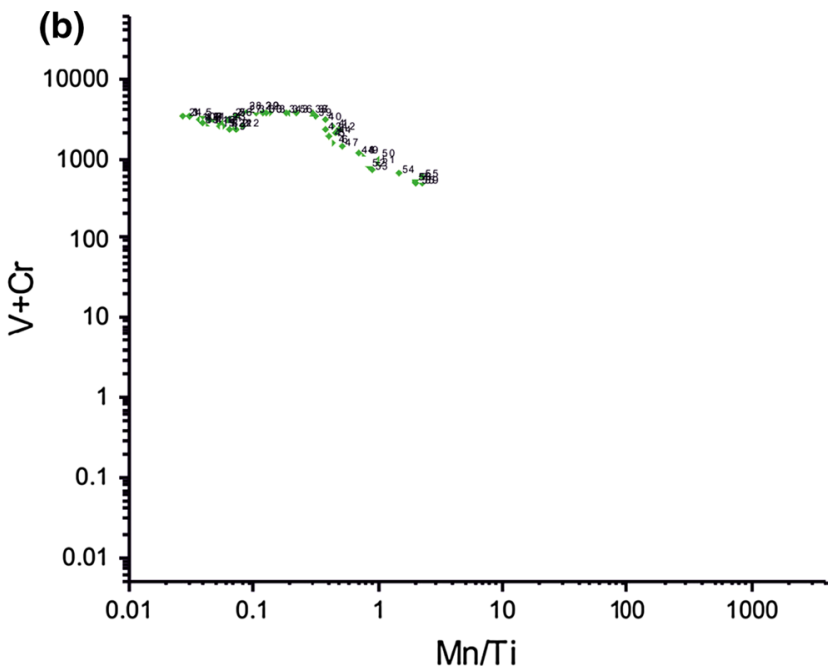

approach alone; $\mathbf{b}$ analysis of the bicolor crystal section from Ufaley (Fig. 3, 59 points), showing the possible variation of the values within one crystal

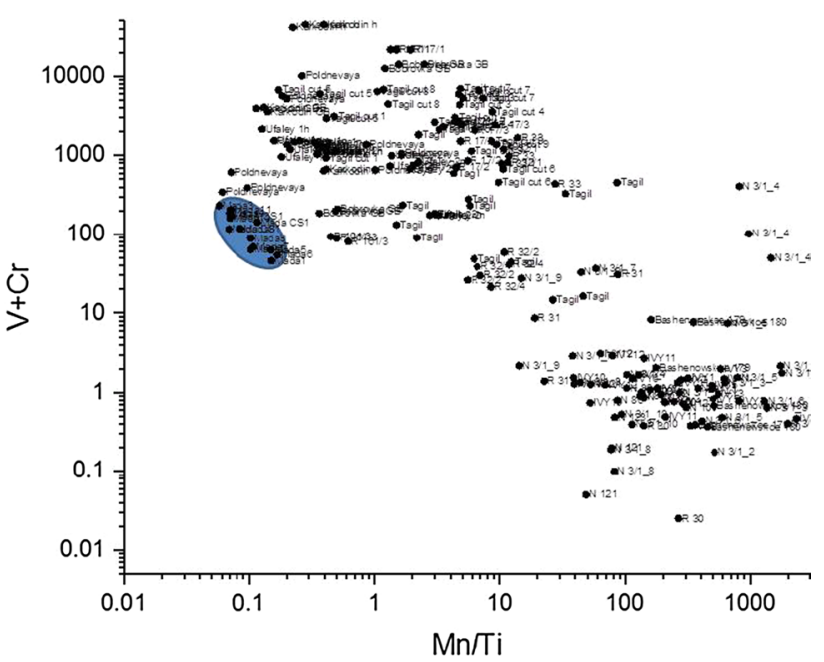

Fig. 6 Inclusion of Madagascar samples into the plot using manganese/titanium ratio vs. the sum of chromium and vanadium shows a good separation from the optically and geologically similar Namibian gems

to have huge errors!). Table 1 shows a summary of ranges found for each element in each deposit.

\section{Conclusion}

Using LA-icp MS it is possible to determine the concentration of several elements that can be used for the determination of the origin of demantoid garnets. From the few locations where this green variety of andradite can be found, 
Table 1 Concentrations of relevant elements in demantoids from Russia, Namibia, and Madagascar in ppm

\begin{tabular}{llll}
\hline Element & Russia & Namibia & Madagascar \\
\hline $\mathrm{Mg}$ & $420-4200$ & $70-1145$ & $300-3400$ \\
$\mathrm{Al}$ & $0-6300$ & $13-910$ & $11,000-109,200$ \\
$\mathrm{Ti}$ & $0-5500$ & $1.5-98$ & $890-3200$ \\
$\mathrm{~V}$ & $0-1970$ & $0-1.5$ & $34-220$ \\
$\mathrm{Cr}$ & $0-43,300$ & $0-100^{\mathrm{a}}$ & $1.6-43.5$ \\
$\mathrm{Mn}$ & $89-1560$ & $15-4980$ & $125-257$ \\
\hline
\end{tabular}

${ }^{\mathrm{a}}$ One single point was $400 \mathrm{ppm}$

only three are of commercial interest for the production of gemstones at the moment, which are Russia, Namibia, and Madagascar. The famous bright green Russian stones owe their color to a high concentration of $\mathrm{Cr}$ and/or $\mathrm{V}$ - which is a good indicator-but not all Russian stones have significantly higher values then other stones. But in combination with low Mn and high Ti concentrations, they can be separated from their Namibian counterparts. Material from Madagascar typically has an even lower $\mathrm{Mn} / \mathrm{Ti}$ ratio, but might have some $\mathrm{Cr}$ and especially V; however, due to their extremely high Al content, they can also be easily separated from all other sources.

What is absolutely necessary for such a model to work is that a significant number of reference samples with proven origin must be available and that the database is always kept up to date as new deposits are still being found. Some rarities might not be assigned correctly by the approach presented here, as not all locations have been included yet into the study but the focus at this time has been the identification of those gems that are currently dominating on the market.

\section{Materials and methods}

Rough demantoid samples were collected from Tubussis (Namibia), Ufaley (Russia), Karkodin (Russia), Poldnevskoye (Russia), Bobrovka (Russia), Bashenovskoe (Russia), and Antetezambato (Madagascar). Cut stones were either cut by the author or taken from the collection of the Austrian Gemmological Society or the collection of Gerhard Brandstetter. Many of the cut stones were only labeled "Russia" with no details of the mine. A total of 42 Russian (126 points), 23 Namibian (69 points), 2 Madagascar (14 points), and 1 multicolored sample from Ufaley Russia (59 points) were analyzed.

All samples were tested with Raman and FTIR spectroscopy to ensure that they were all andradites [11]. Chemical analysis was done by laser ablation-icp MS. Concentrations of $\mathrm{Mg}, \mathrm{Al}, \mathrm{Ti}, \mathrm{V}, \mathrm{Cr}$, and $\mathrm{Mn}$ were measured by laser ablation-inductively coupled plasma mass spectrometry (LA-icp
MS) using a Cetac LSX-213 G2 + laser ablation system coupled to a Thermo Fisher Scientific X-Series II icp MS system. $\mathrm{Ca}, \mathrm{Si}$, and $\mathrm{Fe}$ were also monitored to ensure the smoothness of the laser ablation process. Tuning and calibration were carried out using NIST 610, 612, and 614 glass standards; reference values were taken from Jochum et al. [12]. The laser ablation was operated with a $100 \mu \mathrm{m}$ spot size, a laser energy of $10 \%$ and a repetition rate of $10 \mathrm{~Hz}$. 130 shots were made on each spot and the ablated products transferred to the icp MS with a flow rate of $500 \mathrm{~cm}^{3} \mathrm{~min}^{-1}$ He gas. Each sample was measured at three different spots.

Infrared spectra were collected with a Thermo Scientific iN10MX FTIR microscope in reflection mode using a liquid nitrogen cooled MCT detector. Spectra were collected from 680 to $4000 \mathrm{~cm}^{-1}$ with a resolution of $8 \mathrm{~cm}^{-1}$ and 16 scans were averaged for one spectrum. Raman spectra were collected with a Thermo Scientific DXR Raman microscope using a $780 \mathrm{~nm}$ laser. Spectra were recorded from 55 to $3400 \mathrm{~cm}^{-1}$ and automatically summarized until a signal to noise level of 500 was achieved.

XPS measurements were performed using a Thermo Scientific Thetaprobe device, which was equipped with a monochromatic $\mathrm{Al} \mathrm{K} \alpha \mathrm{X}$-ray source $(h \eta=1486.6 \mathrm{eV})$ and dual flood gun for the surface charge neutralization. The X-ray spot on the measured sample surface was $400 \mu \mathrm{m}$ in diameter. The survey spectra were recorded using a pass energy of $200 \mathrm{eV}$ and an energy step width of $1 \mathrm{eV}$.

Acknowledgements Open access funding provided by Johannes Kepler University Linz. The author is grateful to Ildar Latypov for providing a set of rough demantoid crystals from the Russian localities and fruitful discussions, as well as Prof. Leopold Rössler from the Austrian Gemmological Society and Gerhard Brandstetter for providing samples from their collections. The support from Manuela List and Jiri Duchoslav from the JKU for recording LA-icp MS spectra and XPS spectra is also acknowledged.

Open Access This article is distributed under the terms of the Creative Commons Attribution 4.0 International License (http://creativeco mmons.org/licenses/by/4.0/), which permits unrestricted use, distribution, and reproduction in any medium, provided you give appropriate credit to the original author(s) and the source, provide a link to the Creative Commons license, and indicate if changes were made.

\section{References}

1. Deer WA, Howie RA, Zussman J (1982) Rock-forming minerals. In: Deer WA, Howie RA, Zussman J (eds) Orthosilicates, vol 1a, 2nd edn. Halsted Press, New York, p 919

2. Giuliani G, Pignatelli I, Fallick A, Boyce A, Andriamamonjy A, Razafindratsimba S, Khan T (2017) InColor 2:28

3. Kolesar P, Tvrdý J (2006) Zarenschätze. Rainer Bode, Haltern, p 204

4. Burlakov A, Burlakov E (2017) InColor 2:40

5. Reif S (2017) InColor 2:48 
6. Blaimauer D (2012) Demantoid garnet, FEMtech report

7. Blaimauer D, Hammer VMF, Lehrl M, Wildner M (2013) Der Demantoid aus Nambia. Presented at Carl von Schreibers Forschungspreis an junge Wissenschafterinnen und Wissenschafter im NHM Wien

8. Pezzota F, Adamo I, Diella V (2011) Gems Gemol 47:2

9. Serov R, Shelementiev Y, Serova A (2015) In: Conference Proceedings of the 34th International Gemmological Conference IGC, $\mathrm{p} 34$

10. Schwarzinger C, Ulatowski S, Saywer M (2019) J Gemmol (Accepted)

11. Bersani D, Ando S, Vignola P, Moltifiori G, Marino I-G, Lottici PP, Diella V (2009) Spectrochim Acta A Mol Biomol Spectrosc $73: 484$
12. Jochum KP, Weis U, Stoll B, Kuzmin D, Yang Q, Raczek I, Jacob DE, Stracke A, Birbaum K, Frick DA, Günther D, Enzweiler J (2011) Geostand Geoanal Res 35:397

Publisher's Note Springer Nature remains neutral with regard to jurisdictional claims in published maps and institutional affiliations. 